\title{
CORRECTION
}

View Article Online

View Journal | View Issue
W) Check for updates

Cite this: J. Anal. At. Spectrom., 2020, 35, 1502

DOI: $10.1039 / \mathrm{d0ja90037k}$

rsc.li/jaas

\section{Correction: Quantitative analysis of phosphorus in steel using laser-induced breakdown spectroscopy in air atmosphere}

\author{
Chang Mao Li, ${ }^{\text {a }}$ Zhi Min Zou, ${ }^{\mathrm{b}}$ Xin Yan Yang, ${ }^{\mathrm{a}}$ Zhong Qi Hao, ${ }^{\mathrm{a}}$ Lian Bo Guo, ${ }^{\mathrm{a}}$ \\ Xiang You Li, ${ }^{\text {a }}$ Yong Feng $\mathrm{Lu}^{\mathrm{c}}$ and Xiao Yan Zeng ${ }^{\mathrm{a}}$ \\ Correction for 'Quantitative analysis of phosphorus in steel using laser-induced breakdown spectroscopy in \\ air atmosphere' by Chang Mao Li et al., J. Anal. At. Spectrom., 2014, 29, 1432-1437, DOI: 10.1039/ \\ C4JA00036F.
}

The authors regret the error in the affiliation of one of the authors, Yong Feng Lu, in the original manuscript. The correct affiliation is: University of Nebraska-Lincoln (UNL) and not Wuhan National Laboratory for Optoelectronics (WNLO) at the Huazhong University of Science and Technology (HUST). The corrected list of authors and affiliations for this paper is as shown in this Correction article.

The Royal Society of Chemistry apologises for these errors and any consequent inconvenience to authors and readers.

\footnotetext{
${ }^{a}$ Wuhan National Laboratory for Optoelectronics (WNLO), Huazhong University of Science and Technology, Wuhan, Hubei 430074, P. R. China. E-mail: xyli@mail.hust.edu.cn; Fax: +86-27-87541423; Tel: +86-27-87541423

${ }^{b}$ Institute of Metal Research, Chinese Academy of Sciences, Shenyang, 110016, P. R. China

'Department of Electrical and Computer Engineering, University of Nebraska, Lincoln, NE, 68588-0511, USA
} 